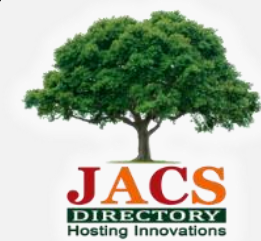

Journal of Nanoscience and Technology

Visit Journal at http://www.jacsdirectory.com/jnst

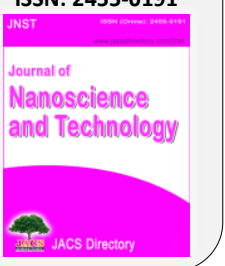

Special Issue on "International Conference on Nanomaterials - 2018" - Alagappa University

Issue Editor: Dr. G. Ramalingam

\title{
Spectral, Thermal and Morphological Characterization of Biodegradable Graphene Oxide- Chitosan Nanocomposites
}

\author{
R. Baby Suneetha* \\ PG and Research Department of Chemistry, V.O. Chidambaram College, Affiliated to Manonmaniam Sundaranar University, Tuticorin - 628 008, TN, India.
}

\section{ART I C L E DETAILS}

\section{Article history:}

Received 21 March 2018

Accepted 29 March 2018

Available online 06 April 2018

Keywords:

Graphene Oxide

Chitosan

Nanocomposite

\begin{abstract}
A B S T R A C T
Graphene oxide (GO) was chemically synthesized from natural graphite by modified Hummers method. The graphene oxide-chitosan (GO-CHI) nanocomposites were synthesized by simple solution-mixing and evaporation method using ultrasonication. The samples were characterized using FTIR, UV-Vis spectroscopy, TG/DTA, DSC, SEM, TEM and AFM. The FTIR spectrum suggested that interactions existed between $\mathrm{CHI}$ and GO as evidenced by the downshift of the $\mathrm{C}=0$ stretching vibration of the amide group at $1653 \mathrm{~cm}^{-1}$. UV-Vis spectra shows a bathochromic shift in bands of GO in the nanocomposite. The optical analysis of the GO and GO-CHI nanocomposites gave a direct energy band gap of $1.02 \mathrm{eV}$ and 1.08 $\mathrm{eV}$ respectively indicating the highly conducting nature of the synthesized nanocomposite. Thermal stability was studied through TG/DTA which showed an enhancement in degradation temperature of chitosan from $175.4{ }^{\circ} \mathrm{C}$ to $302.5{ }^{\circ} \mathrm{C}$ in the composite and DSC studies showed an endothermic peak at $94.55{ }^{\circ} \mathrm{C}$ which is due to the loss of physisorbed water from the surface of the CHI matrix and an exothermic peak at $302.11^{\circ} \mathrm{C}$ due to degradation and deacetylation of chitosan indicating high thermal stability of the composite. SEM micrograph of the nanocomposite showed the presence of the biopolymer chitosan with its porous, rough, granular morphology and the GO with its layered morphology. TEM image of the nanocomposite showed the particle size to be $20 \mathrm{~nm}$ and it also showed the presence of exfoliated GO as a fibrous network on the surface of the chitosan matrix. AFM study shows the value of the RMS coefficient for the nanocomposite as $40 \mathrm{~nm}$ indicating the formation of composite in the nano dimension. It also revealed the presence of rough surface thus indicating the presence of large number of active sites.
\end{abstract}

\section{Introduction}

Graphene is a two-dimensional building block which can be stacked as three dimensional graphite, rolled into one dimensional nanotubes, or folded into zero dimensional fullerenes [1, 2]. The extra quantum confinement of the electrons due to the lack of a third dimension gives graphene various novel properties. For example, electrons interact with carbon atoms in the lattice to create a system that acts like a single mobile charge carrier. The carrier moves over the graphene surface which enables graphene sheets to conduct electricity $[3,4]$. Other complex interactions between electrons and the hexagonal lattice make graphene transparent, flexible and strong [5]. These properties and others have attracted many researchers over the last half-decade to study graphene for a variety of uses $[6,7]$. Graphite is a three dimensional material made up of millions of layers of graphene. By the oxidation of graphite using strong oxidizing agents, oxygenated functionalities are introduced. This makes the material hydrophilic enabling the graphite oxide to be exfoliated in water using sonication, ultimately producing single or few layer graphene, known as graphene oxide (GO). One of the advantages of GO is its easy dispersability in water and other organic solvents. This is due to the presence of the oxygen functionality groups. The presence of these groups helps in mixing the material with ceramic or polymer matrices when trying to improve their electrical and mechanical properties $[8,9]$. Mass production of high quality graphene sheets at low cost is needed for commercial applications. Therefore, it is important to develop environmentally friendly methods for producing graphene nanosheets in large scale.

The chemical approach for producing GO is well suited for mass production because of its low-cost procedure. Furthermore, it can render a large variety of different variants of graphene with chemical modifications $[10,11]$. In view of this, the interest of this study is to chemically synthesize GO through a modified Hummers' method, using natural graphite as starting material and then synthesizing the $\mathrm{GO}-\mathrm{CHI}$ nanocomposites by making use of natural biopolymer chitosan through inexpensive environment friendly simple solution-mixing and evaporation method using ultrasonication.

\section{Experimental Methods}

\subsection{Synthesis of $G O$}

For the synthesis of GO by modified Hummers method, $2 \mathrm{~g}$ of graphite and $1 \mathrm{~g}$ of sodium nitrate were dissolved in $46 \mathrm{~mL}$ of concentrated sulphuric acid in an ice bath. After about 15 min of stirring, $6 \mathrm{~g}$ of potassium permanganate was gradually added into the suspension with stirring as slowly as possible in order to control the reaction temperature below $20^{\circ} \mathrm{C}$. The suspension was stirred for $2 \mathrm{~h}$ and then maintained at 35 ${ }^{\circ} \mathrm{C}$ for $30 \mathrm{~min}$. Next, $92 \mathrm{~mL}$ of deionized water was slowly poured into the suspension, resulting in a quick increase in temperature but which was controlled such that it remained less than $98{ }^{\circ} \mathrm{C}$. After $15 \mathrm{~min}$, the suspension was further diluted to approximately $280 \mathrm{~mL}$ with warm deionized water, after which $20 \mathrm{~mL}$ of $30 \%$ hydrogen peroxide was added to remove the residual potassium permanganate and manganese dioxide to change the color to luminous yellow. The resulting suspension was filtered and washed with deionized water. The sample of GO was dried under vacuum at $50{ }^{\circ} \mathrm{C}$ to a constant weight.

\subsection{Synthesis of GO-CHI Nanocomposite}

GO $(0.05 \mathrm{~g})$ was dissolved in $100 \mathrm{~mL}$ distilled water and placed in ultrasonic bath for an hour until a brown colour was formed. To this, $2 \mathrm{~g}$ $\mathrm{CHI}$ was added with stirring at $27^{\circ} \mathrm{C}$ for an hour at $350 \mathrm{rpm}$. The mixture was filtered and dried at $70^{\circ} \mathrm{C}$ for $8 \mathrm{~h}$. The dried composite were soaked in $2 \%$ sodium hydroxide for an hour and dried at $70^{\circ} \mathrm{C}$ for $6 \mathrm{~h}$ and used for characterization. 


\subsection{Characterization}

The conformation and constitution of the nanocomposites were characterized by UV-Vis and FTIR spectroscopy. For recording UV-Vis absorption spectra, a computer controlled JASCO V-530 dual beam spectrophotometer with DRS support was used. The FTIR spectra were recorded using SHIMADZU spectrometer by pelletizing the samples using $\mathrm{KBr}$ in the frequency range of $400-4000 \mathrm{~cm}^{-1}$. The morphology of the synthesized material was studied using microscopic techniques like scanning electron microscopy (SEM) and atomic force microscopy (AFM). SEM micrographs were recorded using SEM instrument model: JEOL JSM 6360 operating at $25 \mathrm{kV}$. AFM of the samples were recorded using Nanosurf Easy Scan 2 Controller by dissolving the nanocomposites in DMSO after sonication for fifteen minutes and then coating the sample on a glass plate.

\section{Results and Discussion}

\subsection{UV-Vis Spectral Studies}

The UV-Vis spectrum of the GO-CHI composite is shown in Fig. 1. Pure GO (Fig. 1a) shows two absorption peaks one at $234 \mathrm{~nm}$ and another at $304 \mathrm{~nm}[12,13]$. As per literature, the CHI peaks are expected at $240 \mathrm{~nm}$ and $280 \mathrm{~nm}$ [14]. After attachment with CHI, the peaks of GO have shown a bathochromic shift. This shift in absorption maxima might be attributed to the formation of particles in the nano scale. This also indicate the strong covalent interaction between GO and $\mathrm{CHI}$ where the active ester group of GO might have reacted with the amine groups on CHI, forming an amide bond between GO and CHI. Optical analysis shows the band gap energy of $\mathrm{GO}$ to be $1.02 \mathrm{eV}$ and that of the nanocomposite to be $1.08 \mathrm{eV}$. Since these values are within the range of semiconductor indicating that the conductivity of the constituents are retained in the composites thus enabling their application in the field of optoelectronics.
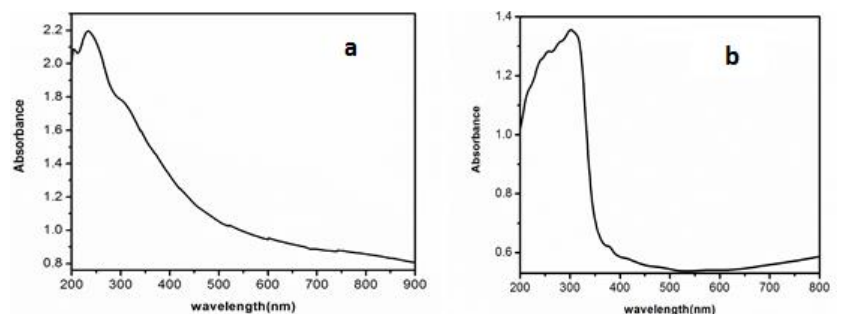

Fig. 1 UV-Vis spectra of a) graphene oxide and b) GO-CHI nanocomposite

\subsection{FTIR Spectra}

The FTIR spectrum of GO as shown in Fig. 2a shows a broad peak at $3386.75 \mathrm{~cm}^{-1}$ in the high frequency area together with a sharp peak at $1650.01 \mathrm{~cm}^{-1}$ corresponding to the stretching and bending vibration of $\mathrm{OH}$ groups of water molecules adsorbed on graphene oxide $[15,16]$. This implies that the sample has strong hydrophilicity. The absorption peak at $1620 \mathrm{~cm}^{-1}$ can be ascribed to the presence of benzene rings [17]. The absorption peaks at $2922.07 \mathrm{~cm}^{-1}$ represent the symmetric and antisymmetric stretching vibrations of $\mathrm{CH}_{2}$, while the presence of two absorption peaks observed in the medium frequency area, at $1650.01 \mathrm{~cm}^{-}$ 1 and $668.61 \mathrm{~cm}^{-1}$ can be attributed to the stretching vibration of $\mathrm{C}=\mathrm{C}$ and $\mathrm{C}=\mathrm{O}$ of carboxylic acid and carbonyl groups present at the edges of graphene oxide [18]. Finally the absorption peaks at $1384.56 \mathrm{~cm}^{-1}$ and $1093.98 \mathrm{~cm}^{-1}$ correspond to the stretching vibration of $\mathrm{C}-\mathrm{O}$ of carboxylic acid and $\mathrm{C}-\mathrm{OH}$ of alcohol, respectively. The presence of these oxygen containing groups reveals that the graphite has been oxidized. The polar groups, especially the surface hydroxyl groups, result in the formation of hydrogen bonds between graphite and water molecules; this further explains the hydrophilic nature of graphene oxide. Fig. $2 \mathrm{~b}$ shows the peaks at 1069,1321 , and $1626 \mathrm{~cm}^{-1}$ correspond to $\mathrm{C}-\mathrm{O}-\mathrm{C}$ stretching vibrations, $\mathrm{C}-\mathrm{OH}$ stretching, and the $\mathrm{C}-\mathrm{C}$ stretching mode of the $\mathrm{sp}^{2}$ carbon skeletal network, respectively, while peaks located at 1653 and $3386 \mathrm{~cm}^{-1}$ correspond to $\mathrm{C}-\mathrm{O}$ stretching vibrations of the- $\mathrm{COOH}$ groups and $\mathrm{O}-\mathrm{H}$ stretching vibration, respectively. These functional groups make GO highly hydrophilic and render it dispersible. In the spectrum of $\mathrm{CHI}$, it is reported in literature that there are two characteristic absorbance bands centered at 1650 and $1591 \mathrm{~cm}^{-1}$, which corresponded to the $\mathrm{C}=0$ stretching vibration of amide I and the $\mathrm{N}-\mathrm{H}$ bending of $-\mathrm{NH}_{2}$, respectively [19]. The FTIR spectrum of the GO-CHI composite showed a combination of characteristic peaks of the pristine $\mathrm{CHI}$ and GO. In the spectrum of $\mathrm{CHI}$, peaks corresponding to $\mathrm{NH}_{2}$ absorbance vibration are at $1591 \mathrm{~cm}^{-1}$. In the spectrum of $\mathrm{GO}$, peaks corresponding to $\mathrm{C}=0$ stretch of carboxylic group is at $1734 \mathrm{~cm}^{-1}$. In the spectrum of $\mathrm{GO}-\mathrm{CHI}$, both of the above peaks https://doi.org/10.30799/jnst.sp208.18040201 disappeared, which suggested that interactions existed between $\mathrm{CHI}$ and GO. Moreover, the $\mathrm{C}=\mathrm{O}$ characteristic stretching band of the amide at 1653 $\mathrm{cm}^{-1}$ was downshifted due to the synergistic effect of hydrogen bonding between $\mathrm{CHI}$ and the oxygenated groups in GO and the electrostatic interaction between polycationic $\mathrm{CHI}$ and the negative charge on the surface of GO. These interactions may have a strong impact on the mechanical properties, swelling, and degradation of the composite [20].

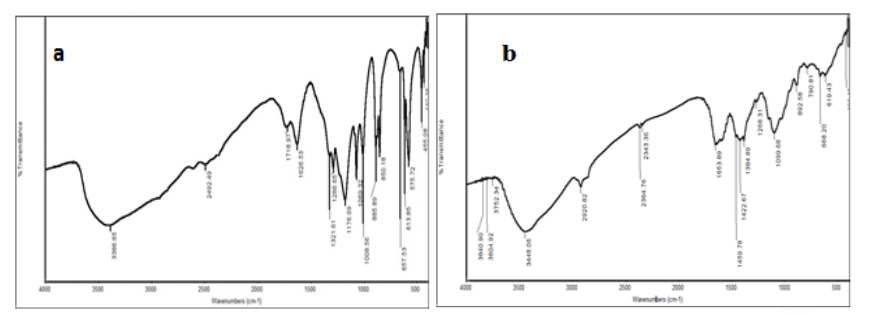

Fig. 2 FTIR spectra of (a) graphene oxide (b) GO-CHI composite

\subsection{Thermal Analysis}

The DSC thermogram of GO-CHI composites (Fig. 3a) shows an endothermic peak at $94.55^{\circ} \mathrm{C}$ which is due to the loss of physisorbed water from the surface of the $\mathrm{CHI}$ matrix with the glass transition at $245{ }^{\circ} \mathrm{C}$ and an exothermic peak at $302.11^{\circ} \mathrm{C}$ due to degradation and deacetylation of chitosan $[21,22]$. The Tg of $\mathrm{CHI}$ as per literature is $175.4^{\circ} \mathrm{C}$ [23]. Due to the presence of exfoliated GO in the CHI matrix Tg of the composite has increased to $260^{\circ} \mathrm{C}$. This increase may be due to the effective attachment of GO to $\mathrm{CHI}$ that prevents the segmental motion of $\mathrm{CHI}$ chains by hydrogen bonding and electrostatic interaction $[24,25]$. Similar result was obtained in TG/DTA studies.

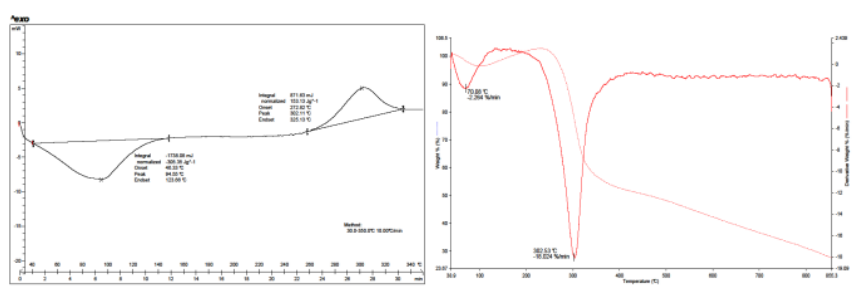

Fig. 3 a) DSC thermogram and b) TG/DTA of GO-CHI nanocomposite

\subsection{SEM Analysis}

In the case of SEM image of GO-CHI composite (Fig. 4) the presence of the biopolymer Chitosan with its porous, rough and granular morphology, and the GO with its layered morphology could be seen. The presence of exfoliated GO is also clearly seen as a fibrous network on the surface of the Chitosan matrix. This is an indication of good adhesion and interaction between chitosan and graphene oxide in the composites.

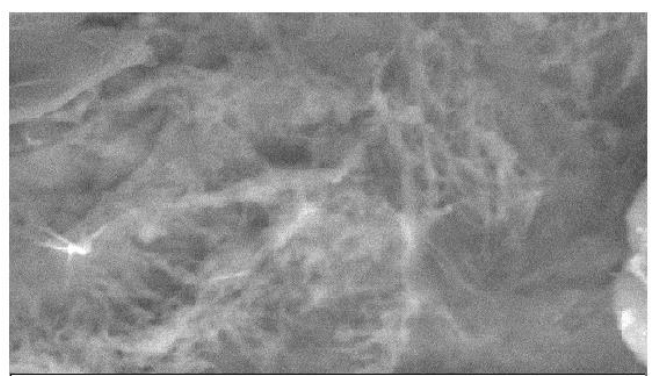

Fig. 4 SEM micrograph of GO-CHI nanocomposite

\subsection{AFM Studies}

AFM spectra was recorded for the nanocomposite by depositing it on a glass plate using DMSO as solvent. Fig. 5 shows the topography $(3.13 \times 3.13$ $\mu \mathrm{m})$ of the surface of GO-CHI nanocomposites. The topography changes within a range of 0 to $106 \mathrm{~nm}$. Analyzing the cross-sections across the surface we see the changes in height amount to several nanometers along the cross-section of $88.9 \mathrm{~nm}$. The value of the RMS coefficient for the nanocomposite amounts to RMS $40 \mathrm{~nm}$ which proves the better development of the surface of the nanocomposite. As a result the nanocomposites may possess a larger specific surface area because the decrease in size always results in an increase in specific surface area. As the surface roughness increases, the effective surface area of the material increases. This increases the number of active sites and number of defects [26]. 

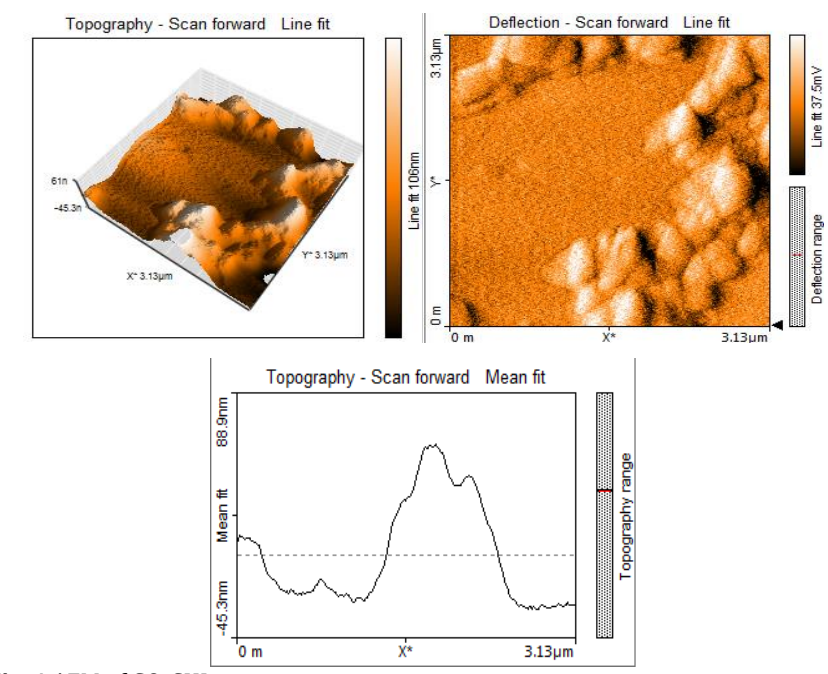

Fig. 4 AFM of GO-CHI nanocomposites

\subsection{TEM Studies}

TEM image (Fig. 5) of the nanocomposite shows the presence of exfoliated GO as dark strands in the matrix of the biopolymer chitosan seen as a light coloured cloud with the particle size of $21 \mathrm{~nm}$. The SAED pattern of the nanocomposite shows its crystalline nature.
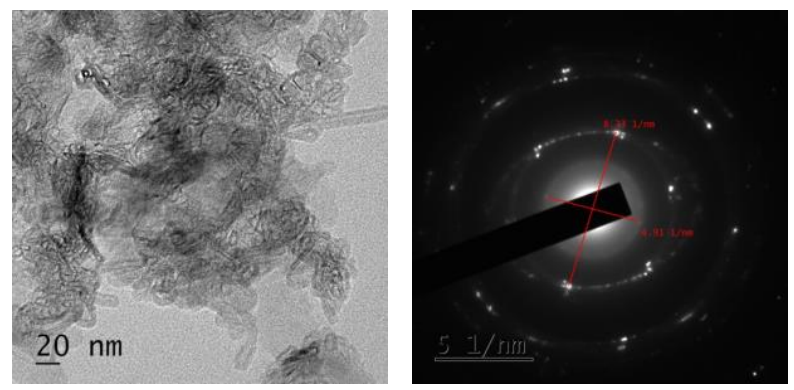

Fig. 5 TEM and SAED pattern of the nanocomposite

\section{Conclusion}

Graphene oxide was successfully synthesized by environment friendly modified Hummers method from natural graphite. Nanocomposite of GO was successfully synthesised using natural biopolymer chitosan by simple solution mixing and evaporation method using ultrasonication. Presence of both the components of the nanocomposite was confirmed by UV-Vis and FTIR spectral studies. These studies also indicate the strong interaction between $\mathrm{GO}$ and $\mathrm{CHI}$ in the nanocomposites. Band gap energy calculations show the highly conducting nature of the nanocomposite. The synthesized composite was found to have greater thermal stability. The presence of exfoliated GO is seen as a fibrous network on the surface of the chitosan matrix from the SEM images. TEM analysis showed similar result with the formation of crystalline nanocomposite with the particle size of $21 \mathrm{~nm}$. AFM images show formation of composite in nanoscale as well as the presence of number of active sites.

\section{Acknowledgement}

The author thanks DST-FIST and UGC innovative programme, New Delhi, India for enabling her to use Jasco UV-VIS Spectrophotometer and AFM. Also the author thanks SAIF, STIC, Cochin for their support to use SEM instrument.

\section{References}

[1] D. De, M. Chakraborty, S. Majumdar, S. Giri, Bandgap engineering through nanocrystalline magnetic alloy grafting on reduced graphene oxide, Phys. Chem. Chem. Phys. 16 (2014) 19661-19667.

[2] B. Garg, T. Bisht, Y.C. Ling, Graphene-Based nanomaterials as heterogeneous acid catalysts: A comprehensive perspective, Molecules 19 (2014) 14582 14614.

[3] A.K. Geim, K.S. Novoselov, The rise of graphene, Nat. Mater. 6 (2007) 183-191.

[4] M.L. Gethers, J.C. Thomas, S. Jiang, N.O. Weiss, X. Duan, W.A. Goddardlll, P.S Weiss, Holey graphene as a weed barrier for molecules, ACS Nano. 9 (2015) 10909-10915.

[5] J.S. Bunch, S.S. Verbridge, J.S. Alden, A.M. Van Der Zande, J.M. Parpia, H.G. Craighead, P.L. McEuen, Impermeable atomic membranes from graphene sheets, Nano Lett. 8 (2008) 2458-2462.

[6] T. Chen, Y. Xia, Z. Jia, Z. Liu, H. Zhang, Synthesis, characterization, and tribological behavior of oleic acid capped graphene oxide, J. Nanomater. 2014 (2014) 654145(1-8)

[7] Z.S. Wu, Y. Sun, Y.Z. Tan, S. Yang, X. Feng, K. Mullen, Three-dimensional graphene-based macro- and mesoporous frameworks for high-performance electrochemical capacitive energy storage, J. Am. Chem. Soc. 134 (2012) 19532-19535.

[8] Y. Cao, J. Feng, P. Wu, Preparation of organically dispersible graphene nanosheet powders through a lyophilization method and their poly(lactic acid) composites, Carbon 48 (2010) 3834-3839.

[9] D. Yoo, J. Kim, J.H. Kim, Direct synthesis of highly conductive poly(3,4ethylenedioxythiophene):poly(4-styrenesulfonate) (PEDOT:PSS)/graphene composites and their applications in energy harvesting systems, Nano Res. 7 (2014) 717-730.

[10] W. Wan, Z. Zhao, H. Hu, J.S. Qiu, Highly controllable and green reduction of graphene oxide to flexible graphene film with high strength, Mater. Res. Bull. 48 (2013) 4797-4803.

[11] S.N. Alam, L. Kumar, N. Sharma, Development of Cu-exfoliated graphite nanoplatelets $(\mathrm{xGnP})$ metal matrix composite by powder metallurgy route, Graphene 4 (2015) 91-111.

[12] C.P.P. Wong, C.W. Lai, K.M. Lee, S.B. Abd Hamid, Advanced chemical reduction of reduced graphene oxide and its photocatalytic activity in degrading reactive black 5, Sci. Tech. Adv. Mater. 8 (2015) 7118-7128.

[13] S. Xu, L. Yong, P. Wu, One-pot, green, rapid synthesis of flowerlike gold nanoparticles/ reduced graphene oxide composite with regenerated silk fibroin as efficient oxygen reduction electrocatalysts, ACS Appl. Mater. Interf. 5 (2013) 654-662.

[14] F. Emadi, A. Amini, A. Gholami, Y. Ghasemi, Functionalized graphene oxide with chitosan for protein nanocarriers to protect against enzymatic cleavage and retain collagenase activity, Sci. Rep. 7 (2017) 42258(1-13).

[15] N. Padmavathy, R. Vijayaraghavan, Enhanced bioactivity of $\mathrm{ZnO}$ nanoparticles - an antimicrobial study, Sci. Technol. Adv. Mater. 9 (2008) 1468(1-7).

[16] T. Zhang, D. Zhang, M.A. Shen, A low-cost method for preliminary separation of reduced graphene oxide nanosheets, Mater. Lett. 63 (2009) 2051-2054.

[17] Y. Si, E.T. Samulski, Synthesis of water soluble graphene, Nano Lett. 8 (2008) 1679-1682.

[18] H. Guo, X. Wang, Q. Qian, F. Wang, X. Xia, A green approach to the synthesis of graphene nanosheets, ACS Nano. 3 (2009) 2653-2659.

[19] Ali Maleki, Reza Paydar, Bionanostructure-catalyzed one-pot three-component synthesis of 3,4-dihydropyrimidin-2(1H)-one derivatives under solvent-free conditions, React. Funct. Polym. 109 (2016) 120-124.

[20] L. Shao, X. Chang, Y. Zhang, Y. Huang, Y. Yao, Z. Guo, Graphene oxide crosslinked chitosan nanocomposite membrane, Appl. Surf. Sci. 280 (2013) 989. 992.

[21] S. Mathew, M. Brahma Kumar, T.E. Abraham, Microstructural imaging and characterization of the mechanical, chemical, thermal, and swelling properties of starch-chitosan blend films, Biopoly. 82 (2006) 176-187.

[22] B. Sarmento, A. Ribeiro, F. Veiga, D. Ferreira, Development and characterization of new insulin containing polysaccharide nanoparticles, Colloids Surf. B Biointerf. 53 (2006) 193-202.

[23] M. Mucha, A. Pawlak, Thermal analysis of chitosan and its blends, Thermochim. Acta. 427 (2005) 69-76.

[24] A. Leszczyaska, K. Pielichowski, Application of thermal analysis methods for characterization of polymer/montmorillonite nanocomposites, J. Therm. Anal. Calorim. 93 (2008) 677-687.

[25] Z. Yao, N. Braidy, G.A. Botton, A. Adronov, Polymerization from the surface of single-walled carbon nanotubes - preparation and characterization of nanocomposites, J. Am. Chem. Soc. 125 (2003) 16015-16024.

[26] T.R. Thomas, Rough surfaces, $2^{\text {nd }}$ Ed., Imperial College Press, London, 1999.

About the Conference: "International Conference on Nanomaterials (ICAN) - 2018" has been organized by Dr. G. Ramalingam, ICAN2018 Organizing Secretary, Assistant Professor, Department of Nanoscience and Technology, Alagappa University, Karaikudi, TN, India at his designated venue on $26^{\text {th }} \& 27^{\text {th }}$ February 2018. 